\title{
Who Says We are Dumb?: Identification of the Causes of Learning Difficulties Encountered by New Immigrant Learners in their Adaptation to the Canadian Classrooms
}

\author{
Buster C. Ogbuagu, Ph.D., M.S.W. \\ College of Arts \& Sciences \\ Department of Social Work \\ University of St. Francis \\ 500 Wilcox Street \\ Joliet, Illinois, 60435, USA \\ Email:bogbuagu@stfrancis.edu \\ Christy C. Ogbuagu, M.Ed. \\ Western Quebec School Board \\ Hull Adult Education \\ 185 rue Archambault \\ Gatineau, Quebec, J8Y 5E3, Canada \\ Email: cogbuagu@wqsb.qc.ca
}

Doi:10.5901/jesr.2013.v3n2p75

\begin{abstract}
When Canada "opened its doors" to immigration in the 1900s, it was not to everyone. It mostly preferred Europeans, whose membership it felt resembled the White, Anglo-Saxons and French, deemed the founders of modern day Canada. All the "Others" were undesirable, due to apprehension with miscegenation and a watering down of "Whiteness" by ethnically non White immigrants. From the 1960s, to the 1990s the "immigration doors" opened just a little wider, and inevitably so, contingent on the sequelae of wars, famine and pestilence that virtually dismantled ancient city states in Africa and Asia. The Refugees have arrived, and the Geneva Convention of 1951 had made provisions for the admittance of those escaping from troubled regions of the world, regardless of color, creed, race or ethnicity. Most of the refugees who arrived in Canada had among them, children born in refugee camps under sundry and bizarre conditions. Additionally, most had never been in school, and for those who did attend school, it was rudimentary and lacked modern educational appurtenances, such as computers, even scissors that they would later find abundant, new, even strange and as "sine qua non" for learning and successful educational outcomes in Canada. The study found that the concomitant of the immigrant learner's experience in refugee camps becomes the problem of integration in and successful educational outcomes at the post-migration stage. New immigrant learners' discomfiture in Canadian classrooms is exacerbated by a meticulously hard-wired racist and Eurocentered system, embodied by an alienating school curriculum and a hostile educational environment, which produce outcomes that are mal coded by educational practitioners as "dumbness." The study proffered suggestions that include anti-racist, multicultural education, competency training and empowerment models as solutions that promote successful and sustainable adaptation, including successful educational outcomes by immigrant learners to the Canadian and other classrooms.
\end{abstract}

Key words: Refugees, immigrant, Immigrant learners, Canadian classrooms, adaptation stress, curriculum alienation, racism, anti-racist competency training, , multicultural education

\section{Introduction}

The present-day educational process aims at promoting individual learning, for the purposes of sustainable participation and integration into an increasingly complex society. The society that we currently live in is imbued 
with a kaleidoscope of cultures, having pluralistic consequences. The 1991 Canadian population census estimated the Black population from Africa and the Diaspora in Canada to be approximately 500,000 (Torczyner, 1997). This does not include the Asian-born immigrant population, which according to $\mathrm{Ng}$ (1998) increased from 14 percent in 1981 to 25 percent and in 1991. Immigrant students are continually arriving at teachers' classrooms faster than was previously imagined or conceptualized. The implication of this is that classrooms, with or without our consent or even awareness are becoming more culturally diverse(Ghosh, 2002; Banks \& Mcgee 1997; Nieto, 1996). Teachers, educators, and administrators therefore, face the challenge of providing suitable environment to accommodate a variety of student cultures and needs (Dunn, Dunn, \& Perrin, 1994). Teachers are advised to use culturally sensitive, culturally relevant practices to meet the needs of every student. Nieto (1999) advises that teachers need to adjust and readjust instructional activities to accommodate a culturally different child (Lewis \& Doorlag, 1999).

While the issue of multicultural education is a well-documented topic in the literature, immigrant students continually find themselves at a loss, with regard to their fate in an unfamiliar school environment, saturated by racist and other normatives. Immigrant students often feel like outsiders to Canadian mainstream cohort (Wilson, 1984), or feel uncomfortable because of negative feelings towards them (Hughes \& Kallen, 1974). Some students tend to become invisible, and avoid having their "learning problems" adequately sorted out (Graham \& Jenkins, 1992). Most immigrant students feel unwelcome, teased, unacknowledged, unmotivated, and afraid. Additionally, these children and youth are battling with issues ranging from past and present life experiences, exacerbated exponentially by classroom affairs (Lee, 1997). They complain over not receiving appropriate and sufficient help to learn the new language quickly enough (McDonnel \& Hill, 1993), and the school environment not meeting their social and emotional needs (Kuperminc, Leadbeater, \& Blatt, 2001).

Following the research problem and its importance to modern Canadian schools, the study has been divided according to the variables demonstrated by the participants and researchers as contributing stressors that do impact on the learning abilities of any immigrant learner, whose social, emotional and academic needs are at variance with the children of the dominant culture. Generally, the study will explore the effects of unsatisfied emotional and social needs of every learner, a fact that is largely informed by a body of literature (Murray \& Greenberg, 2001; Roeser, Wolf, \& Strobel, 2001; Wierzbicka, 1999). Specifically, the study will attempt to identify issues that can and do constitute learning difficulties, areas that generate negative emotions inappropriate for the acquisition of learning (Matthews, Zeidner, \& Roberts, 2002; Welsh, Parke, Widaman, \& O'Neil, 2001) to an immigrant leaner. It also ventures to promote a better understanding of how these issues can become stressors that can and do negatively affect the social, emotional and academic performances of and outcomes for new or immigrant learners attempting to adapt to the Canadian classroom (McDonald \& Speece, 2001; Howes, Phillipsen, \& Peisner-Feinberg, 2000; Powell, 1997). Although the Canadian classroom is the fulcrum of this study, what obtains here is extrapolatable to any classroom in the United States and other European country, with similar pedagogical constructs.

In an attempt to locate areas of necessity to meet the needs of an immigrant or a new learner in a school system, as well as their implications for the learning abilities of such a learner, this paper is divided into four sections. The first section will examine pre-migration experiences or, the effect of a child's past experiences on his or her learning abilities. The cultural as well as emotional issues or burden accompanying that child to the new setting will be examined. The second section will explore post-migration experiences. Also to be explored is the child's experiences in the new setting, which can also promote significant influence on educational outcomes or on how good or bad a child does at school. We shall discuss other sub-divisions in this section in an effort to emphasize the importance of the variables found in this area. The third section is on the perceived general cultural insensitivity of the dominant culture, lack of competency on the part of the teacher and the peers, of where the new learner is coming from, individual and institutionalized discrimination, racism and racialized identity, which are systemically still "maintained through the socialization from generation to generation" (Henry, Tator, Mattis, \& Rees, 2000, p.57), the teasing, the Tracking into vocational sectors, the alienation and poignantly, suggestions on how teachers can promote successful integration and educational outcomes. In addition to interviews, the study will examine literature in an attempt to tease out different variables that might be behind a student's social, emotional and academic incompetence in a classroom environment. Finally, the study will highlight unfamiliar pedagogical areas and techniques to the child, which are likely to add to a new learner's emotional, social, and academic stress and discomfiture. The nitty-gritty of 
unfamiliar teaching materials, equipment and pedagogical styles that bamboozle and present, as major stressors to the child will be highlighted in this section of the paper.

\section{Literature Review}

Our critical evaluation of the causes of an immigrant learner's learning difficulties, combine with numerous literatures on multiculturalism, educational inequalities, racism, and marginalization, which undeniably are at the root of the immigrant learner's learning problems. Additionally, and in order to explore sustainable solutions, we exposed and highlighted several of the psychological constructs facing immigrants and their children before they have any chance of realizing the place of multiculturalism and other widely known, but sequestered and destructive issues in their lives. Most of these issues demand immediate confrontation as soon as a learner sets foot on a new school or culture. Therefore, the study will gain from contributions gleaned from some of the literature on immigrants' adaptation experiences, the psychological distress, and the reason for them, which may contribute immensely to an immigrant learner's quietude and other behaviors in the classroom.

Several investigations (Baffoe, 2012); (Bhagat and London, 1999) have shown that adaptation experience can affect the educational performance of immigrants. These researchers examined the issue of immigrants' adaptation experiences, especially, how they experience psychological distress and uncertainties as they strive to adapt to the new environment. When immigrants arrive in a new country, foreign to their upbringing, they go through depression, anxiety, and acculturation stress (Ritsner \& Ponizovsk, 2003), in their attempt to integrate into their new culture (Hovey \& Magana, 2000). Stiffman \& Davis (1990) define acculturation as "the acquisition of patterns of another's group" (p.329). They list reasons for the acculturative stress, which occur amongst most minority groups as poverty, discrimination, unemployment, low socioeconomic status (Ogbuagu, 2012), and fewer educational opportunities, among other things.

Ullman, and Tatar (2001) compare immigrants' psychological constructs, because of being uprooted from their old life, where they had a support system, to those experienced by war veterans-PTSD, mal-adaptation, nightmares, depression, somatization disorders, which can be comorbid with mood and anxiety disorders with unknown or unclear pathophysiology. Every immigrant has in one way or the other had a feeling of being isolated and lost, in a culture different from the familiar one in his or her native country. According to Northwest Regional Educational laboratory [NWREL] (1991) "almost all immigrant students have been affected by the experience of leaving their home, family, and friends, and settling in a new place with new customs and new languages. Rebuilding their trust and confidence can be a key factor on their later success in the regular classroom" (p.3).

According to $\mathrm{Ng}$ (1998), "the greater the gap between the familiar and the unfamiliar culture in the language spoken, economic structure, technological structure, the more difficult it is to cope" (p.56). Ng maintains that the acclimatization and adaptation process may also be stressful to some immigrants because the cold winter and short daylight hours in Canada limit the outdoor social activities of immigrants, especially for those from tropical regions. This can likely "aggravate social isolation, which may in turn lead to depression and other psychological problems in some people" (p.60).

Similarly, other studies (Bhagat \& London, 1999) (Vernez, Abraharmase, \& Quigley, 1996); have documented the consequences of the indignities of systemized racism, discrimination and marginalization, which can affect self-concept, consequently, promoting low academic performance, uncertainties and alienation. Children have been shown to display some negative self-image as a result of racism, which arise from being bigoted by teachers, peers and other adults (Henry, Tator, Mattis, \& Rees, 2000; Horenczyk \& Tatar, 1998). To most immigrant children, it is not a pleasant experience to be removed from a natural environment, no matter how "primitive," [emphasis added] to an exclusively white, "modern" environment, for those from minority groups. This can "have a debilitating effect on the self-image and group identity of these children" (p.217). The impact of these psychological stresses, which would have started from the immigrant's native country, or refugee camps, can contribute negatively to the learning experiences of any learner, at classroom level.

\section{Theoretical Framework}

This study is informed by an anti-racist, therefore multicultural education theories, which according to Lee (2002) 
presents all facets of education by traversing all subject matters. For Lee, multicultural education is an anti-racist educational system that seeks to include the histories and lived experiences of those historically excised from the curriculum (Dixson and Rousseau, 2006; Dei, James-Wilson and Zine, 2002; Dei and Calliste, 2000; Dominelli, 1997; Dei, 1996). Lee (2002) further argues that an anti-racist education promotes equitability (Aw, 2009) in the cultural and racial realms that define humans as a family. Lee maintains that through anti-racist education, explications of the problematics of social structures and power relationships, including issues of equity are made clearer even if they are yet to be dismantled and reconstructed. Joining the fray, Nieto (1999) argues that hidden in the blue print of discrediting cultural and linguistic differences, itself a form of inequity, is the debilitating burden of assimilation unfairly placed on minority students. Nieto maintains that whereas the new immigrant or minority learner struggles with a deficiency in educational and culturally relevant repertoires in their new settings (Dentler and Hafner, 1997), those students from the dominant cultures present at the threshold of the same institutions with languages, cultures, backgrounds, tools and nuances that are approved and already prewired in them to succeed. This asymmetrical arrangement leaves the minority, new immigrant learner at an unfair disadvantage.

An anti-racist, therefore multicultural education presents as one that equips students, parents and pedagogists with the tools necessary to confront and eliminate racism and all facets of inequality, which currently are encapsulated in ethnicity, gender and all sorts of "outsiding" discourses. It also includes the power arrangements that exist, and who comprise the policy and decision makers and the extent to which their actions or inactions promote the silencing of underprivileged students, parents and other anti-racist educators. The synthesis is arrived at when participants' voices, lived experiences and other essences that define their being are not only heard, but they are presented with opportunities to operationalize them on equal footing with others (Lee, 2002).

\section{Methodology}

The study is a qualitative ethnography, which crucible is on the application of phenomenological interviews. It uses this method to explore the perspectives, content and meaning of an event or meaning that has been decoded by those who experience them. These meanings are then described without embellishment by the researcher (Babbie, 2004; Beins, 2004). Berger and Luckmann (1967) in their "Social construction of reality" argue for phenomenological interviews as consistent with:

"What is 'real' to a Tibetan monk may not be 'real' to an American Businessman. The 'knowledge' of the criminal differs from the 'knowledge' of the criminologist. It follows that specific agglomerations of 'reality' and 'knowledge' pertain to specific social contexts, and that these relationships will have to be included in an adequate sociological analysis of these contexts" (p15).

In the case of Garfinkel (1967) it is an espousal of ethnomethodological study of how social order is produced. Phenomenology therefore posits an assumption that what really matters is the way the observed perceive their event and world to be. Giorgi (1975) expressly argued that "phenomenology is the study of the structure, and the variations of structure, of the consciousness to which anything, event, or person appears" (p.83).

The study used semi-structured face-to-face interviews, having identified themes to prod the respondents along in their narrative (Campbell and Gregor, 2004; Fontana \& Frey, 2000). For the researcher (Kvale and Svend, 2009), what comprise analytical materials to assist in the analysis and decoding of meaning are encapsulated in the transcribed interviews, written text and audio recorded materials. Creswell (1998) speaks to the pertinence of objectivity by the observer as a means of maintaining integrity (Wright, 2003; Hammersley, 2000) of the phenomenon observed, pursuing this by returning to natural scientific methods, and to get a clear picture of the experience, apply intuition, imagination, and universal structures.

There were 45 participants in this study, randomly drawn from a pool of ex-students from five adult education schools or centers in Quebec and Ottawa, the area known as the Canada capital region. Demographically, there were 25 women and 20 male participants. The participants came from regions of Africa, Asia and Eastern Europe and ranged in age from 18 to 55. Most were refugees, while a few others arrived in Canada as landed immigrants. While there were a few participants who arrived with advanced degrees-doctoral, 
Masters, etc. from their country of origin, the medium of instruction or the national language was not English. For these, English language or the lack thereof became the main reason for attending an adult education school. Some spoke somewhat fluent English with discernible accents, while others spoke in smatters, and for these, we had to adjust our language to accommodate them. The participants were issued with Consent forms, which they perused at their convenience, acknowledged understanding of the contents and voluntarily agreed to participate in the study. Key Informants within the community introduced the participants and the researchers to each other. Others were nominated by their friends and class cohort or were former students of one of the researchers.

\section{Research Questions}

The study focused on issues that were perceived to be culpable in the learning disabilities of an immigrant/new learner in a school environment. The research questions posed were:

How can teachers articulate the causes of learning difficulties encountered by new immigrant learners in their adaptation to the Canadian environment?

How can the unmet social and emotional needs or "incompetence" of an immigrant learner possibly become major contributors to his or her learning disabilities?

\section{Limitations of the study}

Most of the researches on immigrants' experiences are on adaptation and acculturation struggles. Conversely, there still is limited research on immigrant experiences of younger children. This paper also admits culpability in over generalization of immigrants' experiences with such a rather small sample size. Most of the ethnographic studies have been on adults' experiences (Omeri, \& Atkins, 2002; Bhagat, \& London, 1999; Ng, 1998) and adolescents' psychological stress (Ullman, \& Tatar, 2001; Horenczyk, \&Tatar, 1998). This study did not cover the experiences of the younger [child] immigrant. More research is needed to articulate children's experiences and on some of the reasons some immigrant children may feel academically inefficacious.

\section{Conceptual Framework}

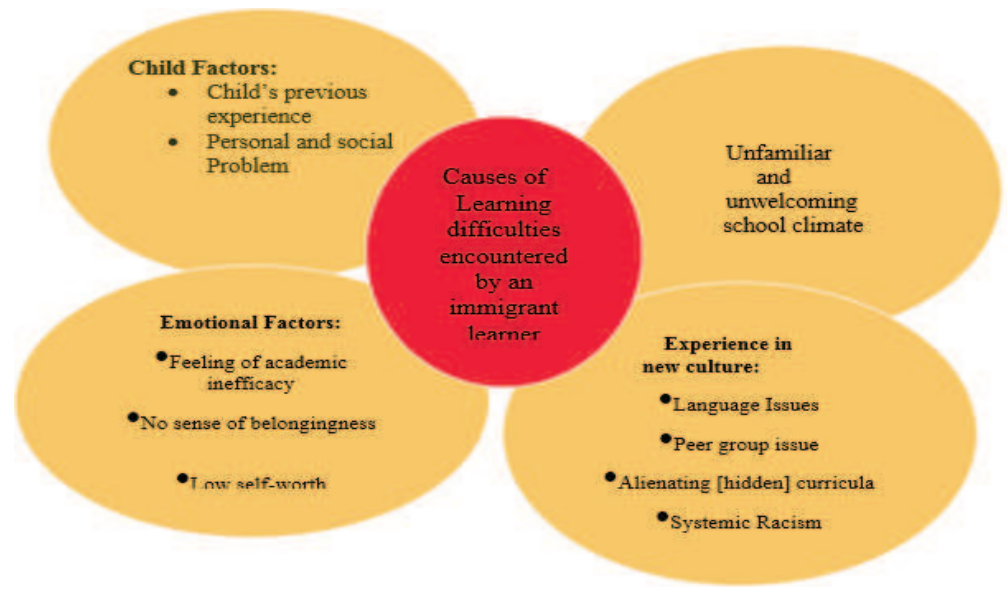

\section{Concept 1.}

\section{Background}

Argues Lee (1997), many of today's Canadian classrooms incorporate a kaleidoscope of cultures. These different learners often have very different life experiences. Some of these learners are immigrants, who have had a 
number of life experiences, some quite unpalatable, which can create or impact upon existing academic learning problems in classroom affairs. Lee further supplies that the four variables that negatively impact the immigrant learner include: the child's previous social and personal problems, learner's unfamiliarity with the school culture, other experiences in the new culture, such as problems with systemic racism, the language, with the use of computer, peer group issues, and low feeling of self-worth. In line with this treatise, Maslow (1997) hierarchy of needs contends that when an individual has a need (hunger, love, security, esteem need, self-actualization need) the memory can be overwhelmed as well as perception and emotion, which can result in learning problems. Realizing the causes of learning difficulties has important implications for teachers, parents and counselors trying to meet the needs of immigrant learners.

\section{Emergent Themes \& Discussion}

Pre-migratory experiences, post-migration experiences, unwelcoming and unfamiliar new culture, language issues-the French/English dichotomy, peer group issues, alienating curriculum, racists educational system, child's emotional, social, and academic stress.

\section{Discussion}

\subsection{Pre-migratory Experiences}

Research (Timotijevic, Breakwell, and Glynis, 2000) has shown a high likelihood of variations in individual migratory experiences, and in the way these immigrants display pre-migratory experiences. To this extent, different immigrants have diverse pre-migratory experiences, which ultimately account for how they adapt or not adapt in their host country. Studies have noted that some immigrants experience great traumatic stress as a result of war (Bhui et al. 2003). They found out that on account of war, refugees are at a "higher risk of psychiatric disorders such as depression, suicide, psychosis, post-traumatic stress..." (p.35). This qualitative study of a good number of Somalians at the time showed that 86 percent of men and 96 percent of women sampled by the authors stated that they left their native countries because of risk to their lives. Conversely, 60 percent of the respondents in our study, who arrived in Canada from Kosovo, Rwanda, Burundi and the Democratic Republic of Congo, stated that they left as a result of oppression on the basis of race, ethnicity, or religion even in their own country. Most of the respondents in this cohort witnessed the massacre of entire family members by fellow countrymen and women.

There are other reasons. Bhui, et al (2003), have also identified other traumatizing events, including famine, clan rivalry, ethnic cleansing, and torture. Torture, according to them, has been found to contribute to mental disorders among refugees. Children have been known to experience psychiatric disorders from these. Still some, having grown up in war-torn countries as orphans resulting in "poor moral development and poor school performance" (p.705).

Additionally, reports of war and ethnic cleansing have been heard in some other countries like Bosnia Herzegovina, Rwanda and Burundi, Namibia, Armenia, Ukraine, the Holocaust-Jews, Cambodia, Guatemala and Darfur (Kiernan, 2009; Power, nd.). Other immigrants were said to be fleeing state-sponsored torture, as in the case of South Africa, and Chile, and as a result have symptoms and behavioral dysfunctions consistent with nightmares, insomnia, startle reaction, intensive grief and difficulty with concentration (Boehnlein, 2002). Boehnlein sums up the extent to which these experiences can impact on an immigrant, who could eventually become a learner in a classroom:

Some children become pupils of war with continued antisocial behavior and aggressive feelings that perpetuate the cycle of violence..." Boehnlien continued that, "successive threats along a continuum of stress faced by refugees and other survivors of human rights violation can compound each other to challenge multiple adaptive systems at both the individual and communal levels" (p.705).

Searight (2003) suggested that immigrants who had experienced war-related trauma should receive medical attention urgently. He cited an example in the United States where immigrants from Bosnia were given medical attention up to eight months after their arrival. The only unfortunate thing, he lamented, was that by the period that time frame had elapsed what he called "obstacles to access" would prevent them from getting such 
help (p.92). Consequently, and according to Searight, from the 350,000 Bosnian immigrants that came to the U.S. in the past five years, 40 percent of the number met criteria for depression, and 25 percent exhibit posttraumatic stress disorders. So the ease and adaptivity that immigrants have of their learning depends on their mental well-being. Based on the above studies, on the diversity of experiences by different immigrants, Keogh, Gallimore, and Weiser (1997) mandated that there be "a broader range of definitional criteria" for evaluating "major implications for understanding learning disabilities" (p.108). They suggested that teachers consider the kind of "preliteracy experiences" children had before they are designated as learning disabled in their new environment.

\subsection{Post-migration Experiences}

Any transition affects children's lives for better or for worse. Changes can be in form of residential, neighborhood or school, even class changes. Indeed, this is an everyday occurrence for human beings, who will experience loss of friends and unfamiliar environments brought on by such changes. The effect of such changes can manifest as low academic performance or behavioral problems in children (Kohen, Hertzman, \& Weins, 1998). In fact, Kohen, Hertzmen, \& Weins assert, "school moves increase the risk of academic performance" of school children (p.iii). Expanding on this assertion, these researchers remind all of us that as children move, they lose their already established personal networks. There is likely to be "loss of social relationship" (p.2), which brings with it loss of their emotional resources. Thus, they advise that schools should provide additional support to any new child in a school. The refugee students in the study admitted to having lost by death or other means, parents, siblings, family members, most of their relationships, homes and the familiar, and that sometimes the last thing on their mind was school or concentrating on school work.

In light of these arguments, it is little wonder that immigrants go through a lot of changes in the new, foreign environment. As they find themselves in unfamiliar, and sometimes, unwelcoming cultures, these myriad of changes result in culture shock, financial problems, and the resulting psychological distress (Baffoe, 2011; Ng, 1998). These experiences vary according to the immigrants' pre-migratory experiences, and how welcoming the new culture is. $\mathrm{Ng}$ puts it aptly with the acknowledgement that, "every encounter with the new place may represent a new experience" (p.55).

\subsection{Unwelcoming and unfamiliar New Culture}

New experiences can be very distressful to immigrants. In admittance that migrating from a native country is a very stressful life experience in itself, Rotenberg, Kutsy, \& Venger (2000) opine that the process of immigrants integration into their new culture and its adaptative problems in either personal or family crises, not only affect and elevate their level of stress, but also can continue up until three to five years after the changes. Added to the stress is when an immigrant has a feeling of being isolated because they feel unwelcome, as a result of people's attitudes towards them, especially when they are treated as culturally and linguistically unfit (Vernez, Abraharmase, \& Quigley, 1996). The new learner immigrant participants in this study expressed a feeling that they did not feel welcome by fellow students and staff. Some of the students who were asked to write poems felt flustered and did not even begin to comprehend where to begin because poetry was not a part of their culture and language repertoire.

In the current study, six students confessed to being too shy and intimidated to be noticed by other students as clueless about the use of a computer; of course, because they came from a country where they never had an opportunity to use a computer before their Canadian sojourn. One of the students asked the teacher [an immigrant whom the student felt understood his predicament] if he could stay after everybody was gone for help with certain basic computer skills. He had no computer at home so the school was the only place he could use a computer. As a new immigrant with children he could not afford a computer either. The teacher stayed back after school with him to help show him how the keys work, using the typing tutor software, and how to save his files when he types his school work, etc. As a grown man with a family he did not want to look stupid, according to him, in the presence of other younger students, who cared less about this older adult from a strange culture and environment. 


\subsection{Language Issues}

Various types of integration, as well as linguistic problems define the post-migratory experiences of immigrants. The issue of language has been one of the most important areas that pose serious problems to immigrants as it impinges negatively on learners' adaptation and academic success. Of the 45 participants in the study a whopping 93 percent or 42 new learner respondents did not have English as their first language, a situation that they admitted made learning a challenge. Although many literature on multiculturalism, which the proponents argue were written to "assist the newcomers to Canada" (Fleras \& Elliott, 2002, p.92) is very laudable, but the extent to which that is achieved is in doubt if linguistically and culturally diverse learners still encounter a factor like limited English proficiency that do impact on their academic performance and outcomes.

One of the respondents in the study declared that she was placed in a special class because the first time she came to a class on her Canadian arrival she was too shy to speak. Secondly it was a French class. As a girl from Congo, she spoke French in Africa, but the French she was spoken to in Canada was dialectal, Québécois. At the beginning, it was difficult for her to comprehend, but she got it later. By then she had been 'diagnosed' as a student with learning difficulty and was placed in a special class. She was so unhappy that she dropped out at 16 and decided to attend an adult education school. Of course, every teacher who had her at school (adult education school) agreed she was a gifted student. She got all A's in every subject, including English, which was her third language.

If according to Delwyn \& Tattum (1992), "language makes possible the richness and variety of human social life" (p.17), it is not surprising, therefore, that a child who has a language problem would have problems socializing with other children in and out of the classroom setting. Most of the new learners in the study, including those with advanced degrees in languages other than English were afraid to engage in class discussions, contingent on their experiences with being ridiculed by others from the dominant cultures (Ogbuagu, 2012). Understanding the linguistic needs of an immigrant learner is very vital in order not to misunderstand and misinterpret the demeanor of such a learner as learning disabled.

Presently, there exists a growing body of research on the characteristics of immigrant learners in terms of their English proficiency in their new culture. A measure of an individual immigrant's traditional culture and the scope of the usage of English, as a second language, from the country an immigrant leaner comes, determine his or her English proficiency. The issue of limited English proficiency has been a very sticky point vis-à-vis the extent of the adaptative problems most of the immigrants have in their new cultures (Ogbuagu, 2012) as the schools in the new culture continue the socialization process started at childhood. The sum of the process of socialization by the family, church, school, media, friends, started early in an immigrant's life struggles for continuity in the new culture.

As observed by Lee and Sheared (2002), when immigrants leave their native countries, not only is there cultural discontinuity but also socialization problems and language discontinuity. The rate with which the continuity is restored in the new culture might be at a snail's speed because of the learner's limited language proficiency. The immigrant learner, as a result, may feel marginalized and isolated. Some studies have highlighted the limited English proficiency of some immigrants as inimical to their timely adaptation. Lee and Sheared contend that this type of feeling adversely "affect the development of student's self-concept and academic performance and promote high drop-out rate among minority and immigrant students" (p.30).

Similarly, using Vygotsky's perspective on the social nature of human mental functioning, which entails the use of language as a cultural tool or as a mediational medium, suggests that limited use of a language by the immigrant leaner in the new environment also limits the person's mental functioning (Wertsch \& Tulviste, 1992). In light of this, Gredler (1997) is in agreement with the two authors above that language is said to "regulate social existence" (p.242). Speech and written language are the prerequisite tools used to maintain social relations. Human's sociocultural experience aids in the development of mental functioning. This is a proof of the interactive nature of language.

From the foregoing, the socialization patterns in the immigrant's new culture will be agonizingly slow, if language proficiency of the learner in the new environment is limited. The remedy to this venture, suggest Lee and Sheared (2002) is that "those teaching individuals whose primary language is not English and whose socialization patterns have been developed in another culture, must pay attention to how we can use formal and informal socialization to help students in our classroom" (p.28). They see the need for educators to ask 
themselves such questions as whether the texts and curriculum reflect immigrant learner's lived experience. Another similar question is whether the texts and curriculum give any voice to immigrant learners, even when they have language problems? Regrettably, this was not the experience of the respondents in the study. In the new culture, wouldn't it be difficult doing that, if the linguistically different learner were seen as an idiot?

Exposito and Favala (2003), therefore, lament over how immigrant students struggle with language as one of the social constraints in their attempt to adapt to new environment. According to them, it does not make it easier for the new learners when teachers treat such student's limitations as deficits, because doing that will make them feel disadvantaged and disillusioned. What is rather very helpful to them is when teachers honor their culture and language (Lee, 1998). In this fray, Nieto (1999) agrees that using any negative attitudes towards any language or culture that is different from that of the mainstream official norm is an attempt to discredit the experiences and knowledge of those students who are linguistically different. Nieto contends that it is very unfair to treat the culture and background experiences of some students as more privileged while those of other students with languages other than English or with different accents are made to feel shame. Rather, according to Nieto, what they need is assistance with their English while acknowledging their intelligence. Might we add that the Great Pyramids of Giza, Egypt, which architectural design still baffles modern day scientists were not constructed by English speakers.

As immigrants find themselves in unfamiliar environments, the required interactive processes in any social setting are limited by language problems. The issue of difficulties with language appears to be one of the most stressful areas in an immigrant's attempt to adapt to a new culture. According to Duran, Dugan, \& Weffer (1998), language problems could force some minority students to lag behind their English-speaking counterparts in the educational achievement level. The reason for this, they point out, is that "the sequence of effects was that English proficiency influenced reading scores, which in turn influenced both course taking in science and achievement test scores" (p.312). Similarly, students with limited English as suggested by the respondents in this study, face a lot more challenges because of the expectations of the course work in other subjects. This arises because of their lack of reading skills in English and not fully understanding the teacher's discourses.

Learning happens in a social interaction, and the use of language as a cultural tool is one of the most important facilitator of learning. This is so because learners use language to sort out their thoughts about things, as language and thoughts are interdependent (Bruner, 1985). The participants in the study clearly and painfully stated their struggle to sort out those thoughts in a second language, a struggle that was amplified by teacher apathy. Duran, Dugan, and Weffer (1998) providing supporting evidence in their study, point out that an immigrant's limited English proficiency limits the description of the events in the classroom in student's words by the student. Their study noted a student who wrote what the teacher was saying in English in her mother tongue, because she lacked the English words. For this reason, Pailliotet (1997) cautions that if an immigrant student is quiet in the class, it might not mean that the student is uninterested or dumb. Rather, he states that limited English proficiency can be a source of stressful experiences for some minority students. Pailliotet's study opines that immigrant students loose their confidence and have feelings of being voiceless, especially, if there is a lack of understanding on the part of a native speaker, having the power to judge them; and judge them they do.

In fact, in a very recent study, Bermau, Lang, \& Erez (2003) provide another insight by arguing that adaptation of an immigrant can be speeded up if there are intensive language classes, as this can mean a huge pay off (Chiswick, \& Miller, 2007) Accounting for this, is that an immigrant learner's inability to communicate in host country's language will not only be a source of stress but decreases their occupational success (Shields, \& Price, (2002) as well as limits their assess to social interaction.

\subsection{Peer Group Issues}

At home, parents are the most important significant other, asserts (Delwyn \& Tattum, 1992). However for children and young people when they enter school these significant others that satisfy basic needs of acceptance and security change to become "teachers and peers" (p.104). Thus a child can hold a different selfconcept at school as a friend, pupil, and "clever boy" praised by the teacher, member of a play team, which if taken away from an immigrant learner would lower his or her self-image. That is why to Delwyn \& Tattum playtime might not be a happy time for a child, after all. Research shows that one of the factors that help an 
immigrant self-integrate is the provision of friendship by peers (Horenczyk, \& Tatar, 1998). Ullman \& Moshe (2001) examine the effect of immigration on life satisfaction, self-esteem, and self-concept among adolescents. Their finding shows that immigrant learners feel distanced and misunderstood by their social peers, following immigration. All the students in this study, especially the females among them expressed how they were ridiculed by the native speakers when they made sentences, presented in class or tried to socialize with their native peers.

Finch, \& Vega (2003) conducted a study with immigrant Latino-origin adults on the effect of social support on health. Their study shows that there is an evidence of a high good health status observed among immigrants with "high levels of social support" (p.109). It is true that there is an association between acculturation stress and immigrants' development of health problems. However, according to them, increase in social support also increases healthy interaction with other individuals, greater involvement in various activities, and greater emotional support. Apart from the benefits of peer social support on an immigrant's health, several other studies also buttress that positive peer support can impact positively on an immigrant's sense of belonging and identity formation. Additionally, high English proficiency of immigrants in their new culture (Phinney, Romero, Nava, \& Huang, 2001; Birman, 1998), increases immigrants' assimilation rate into this new culture (Birman, Trickett, \& Vinokurov, 2002).

On the other hand, other studies, though not directly on the impact of peer supports on immigrants, insist that peer support generally, which constitutes one form of social support has a "stress buffeting effect" (Dumont, \& Provost, 1999, p.346), and reduces low self-esteem and depression on adolescents' lives. Supporting this claim, Turner (1999) includes its effect on the psychological behavioral factors, and self-efficacy. LaGreca, and Lopez (1998) sum it up by adding that just perceived peer support or the lack thereof can cause social anxiety and interest in schools, among adolescence, while Hetch, Inderbitzen, \& Bukowski (1998) add that peer rejection can result in depressive symptoms in children. Peer support is particularly important to adolescents, in fact to everybody. Tattum (1992) demonstrates the importance of peer relationship in everybody's life:

They are important sources of companionship and recreation, someone with whom to share advice and valued possessions, are confidants, critics and allies and provide support in times of stress and transition to a new class or school. By the final year of primary school, ten-year-olds consider friendship to be a sharing of inner thoughts and feelings. They understand that a friend is a special person with whom you enjoy mutual respect and affection. In this way children realize that acts of friendship could change a person's feelings from lonely and sad to being wanted and happy..." (p.129)

\subsection{Alienating [Hidden] Curricula}

When there are diverse students whose native culture is at variance with the school they attend, they inevitably differ from their peers not only in language, but also in cultural background. Therefore (Nieto, 1999, 1996; Lewis, \& Doorlag, 1991) recommend multicultural education and the need to change some instructional procedures to accommodate the needs of an ever growing diverse students. Nieto (1999) seemingly agrees that the curricular and pedagogical approaches in a new school are some of the factors that can either impede or promote an immigrant learner's learning, especially if the content of the curriculum sounds foreign to such a student. Some immigrant learners come from countries where they have never read a single children's book. When references are made to such materials in class, they feel left out and may "zone" out.

Some teachers expect minority students to adjust to the school, instead of adjusting the curriculum to the cultural and linguistic mix of students in the class. How can a teacher do that with close to thirty students from different cultural backgrounds, one may ask? They don't. Henry, Tator, and Rees (1995) give a shot at an answer as they suggest the use of hidden curriculum by teachers. "The hidden curriculum", according to them, "includes teachers' personal values, their unquestionable assumptions and expectations, and the physical and social environment of the school...", as well as such questions as "What learning materials are used? How is knowledge transmitted? What kinds of knowledge are absent, ignored, and denied?" (p.177).

40 participants or 88.9 percent of the 45 respondents had neither seen nor touched a computer prior to their Canadian Odyssey. Here they were in class and were expected to touch and begin interfacing with them, in tandem with the natives, a thoroughly frightening experience. Yet, some teachers, contingent on their cultural incompetencies, or hidden curriculum were quick to express bewilderment at this so-called deficiency. The 
participants informed that several teachers expressed mocking surprise at some of the student's lack of dexterity in using a pair of scissors. Due to their cultural incompetencies, they did not have insight into the fact that most were born and remained in refugee camps, where day-to-day survival was all before being bundled as it were, to Canada, while others were socialized in educational systems and cultures that did not have such strange objects as scissors in their repertoire.

One of the participants in the study, an adult student recalled being placed in a class, where he was required to write poems, including a sonnet, and of course the influence of the English style of poetry. Coming from a country where all he experienced was war, he had never heard of Shakespeare, and had never, ever written a poem. As the student later learned, the teacher, herself an immigrant, understood the student's discomfiture, whispered so other students would not hear because she saw that he felt too shy to admit that he did not know, never heard who Shakespeare was and had never written a poem his whole life.

Many immigrants, especially the ones from war-torn countries, are at Grade 1, 2, or 3 reading levels. Most of them are really ashamed to admit that, until a competent teacher notices; and there are few. How could they not? As children they never had the opportunity to read books. No one sang them a lullaby or read them to sleep. One of the respondents stated a requirement on her part to analyze at least one children's book she read as a child. She read as a child? She said her teacher was surprised she has never seen any children's book, a situation that embarrassed and further alienated and skewed her learning curve. Perhaps, if the teacher was culturally competent, she would not have been this shocked and would have had a handle on how to deal with such learners.

An attempt at that question is provided also as Nieto (1999) speaks to a student's lived experiences not reflected in the school curriculum; a case where there is a great mismatch between what is in the curriculum and students' lived experiences. When that happens, the excluded student feels less important and unmotivated.

\subsection{Child's emotional, social, and academic stress.}

One of the problems that can cause great academic stress is use of unfamiliar teaching materials. An immigrant learner who is coming from a country where she/he has never used a calculator, a ruler, pencil, scissors, a particular text or a computer will feel academically inefficacious when those materials are used in class as was the experience of a large number of the participants. Many of them expressed that they felt very embarrassed to admit and ask for help, for fear of being ridiculed and branded misfits. The outcome was that they withdrew, felt alone, developed low self-esteem and even detested school. As stated earlier, some colleagues of one of the co-researcher of this study have expressed their shock at encountering high school and even college immigrant learners who have no idea how to use the computer keyboard. Such immigrants could be coming from countries too poor to afford such "leisure" or have been born, raised and lived all their life in refugee camps. Both researchers are able to relate to the students' experiences as both are not digital natives (Martin, 2011), had no computer knowledge or even used a computer prior to their Canadian immigration and were utterly discomfited the first time its use was mandated for them (Duran, Duran, Ramirez and Perry-Romero, 2004). The only thing going for the two researchers when they arrived in Canada was that British imperialism had forced them to learn to speak the English language, albeit with a "foreign" accent. What usually occurs in the case of students who neither speak English nor are digital natives is that some withdraw to themselves or quit school, a finding with some of the respondents in this study.

\subsection{Personal anecdotal experience}

Ours and children's experiences and observed difficulties, being immigrants informed some of the assertions in this research. They are, and count as our lived experiences. Having come from a different country several moons ago, we have personal experiences related to the extent to which a child's social and emotional needs/incompetence can put that child at a great risk of being labeled learning disabled. Some of our children were actually referred to doctors for assessment in an attempt to locate what teachers termed learning disability. A psychologist, who assessed one of our children over a one hour period recommended tracking to a vocational program, a suggestion we immediately scoffed at. Another boy from a country where computer use is not common was referred to the school psychologist for assessment. No one thought for a moment that all these 
children needed was time and understanding to learn. Compounding the issue is that some of them, old enough to have known how to use a calculator or a computer find it difficult to confess their problem to the teacher. At one point and following unrelenting teacher and administrative pressures, we nearly acquiesced to the assumption by teachers that two of our children actually had serious learning issues. In that instance, one of our sons was assessed by a psychiatrist over many, painful sessions. All the time we knew that nothing was wrong with him, but felt [we were new immigrants] powerless to challenge the Eurocentered models that were the fulcrum of the assessment and remediation pronouncements. This experience largely informed our longing to apply psychological constructs in the conduct of the study.

\title{
10. Recommendations for New Immigrant learner adaptation
}

Making recommendations related to inclusivity in many facets of society, especially education does not pretend to be an easy endeavor. This is contingent on recommendations being subjective and constructed from the myriad of prisms through which we see issues. If we are the ones who benefit from the situation, it is more likely that we will pursue any attempt to dislodge us from our privileged pedestal. However, if we represent those who do not benefit, therefore are oppressed, we tend to pursue our mission of social justice and equality with the same vigor and fervor. In order to appropriately enter the fray of educational inequalities remediation, the following represents an important resume of the implications for systemic educational practices on the exclusion of new immigrant and racialized learners, as well as remedial and deconstructionist approaches.

\subsection{Schooling \& the educational environment}

The school, which is the crux of the educational system, presents as a source of new values for children and adults, but especially immigrant types. This assertion maintains an unimpeachable stance, since the school and educational system present as forum, where children share what they have gleaned from significant others, books, peers, teachers, instructors and mentors (Sandoval, 2002). Here, the influence of peer groups and, peer pressure assume gargantuan dimensions in the lives of young learners. For the Black or minority children, the impact of school and school environment is amplified in the formation of identity, reconstruction thereof and promotes or demotes individual, group and community development. Connolly (1998) argues that:

\begin{abstract}
...discourses on race also have real material effects on the schooling of Black and Asian children...the popular discourse that Black boys are volatile and aggressive creates a tendency for some of them to be labeled in this way and therefore more likely to be chastised and disciplined by teachers and other school staff, even for things that they have not done. This can act to alienate some Black boys from school, and therefore impinge upon their overall educational performance. A self-fulfilling prophesy appears to come into operation at this point, where certain Black boys do not do well at school and even begin to resist what they feel to be unfair treatment on behalf of the teachers, only then to be labeled as being 'less able' educationally and more likely to present 'behavioral problems' (p.13).
\end{abstract}

Systemic racism in the educational environment is soundly vilified, in part due to certain acts of omission and other instances completely, owing to most acts of commission that have been found to negatively impact on the learning curve of students of color (Nakkula and Toshalis, 2006). The fact that the school demands and operates on the ethos of competition, individualism, materialism and consumerism, promotes failure when some students are not in compliance. Whereas students from the majority culture already have the aforementioned variables as appurtenances of their socialization and as integral to White privilege, colored and minority students do not, therefore unable to compete successfully. What this means is that purposeful design flaws appear to target minority students disproportionately and indefinitely (Freire, 1985). Minority students as products of a racist society, lack most of these demands by the school environment, especially due to the dearth of exemplary, educationally-minded models, (Foster K.M., 2005 and Foster, M., 1991; Wien, 1976) in their communities. Therefore, what minority students are required to bring to school [in the absence of role models that are expressed in the school environment] present as diametrically opposed to the talents and skills they are socialized into, and subsequently bring from their homes and communities. The result is alienation from school, as they sometimes perform below standards [as is expected of them], inevitably getting tracked into remedial or 
vocational programs. Worse still, most dropout entirely as a self-fulfilling prophesy (Fleras and Elliott, 2003; LeCompte, and Dworkin, 1991). According to the Children's Defense Fund (2005), systemically and racially engineered gaps in schools and other social environments account each day for:

1. 2756 high school students drop out

2. 5 suicides by children and teenagers

3. 8 child and teen firearms homicide

4. 367 birth by mothers with little to no access to prenatal care

5. 4,356 under 18 children arrested for criminal activities.

Rassool (1999) conducted a research on the life histories of a group of first and second-generation immigrant pupils, from the African and Asian Diasporas, in an inner-city comprehensive school in Britain. Through narratives, the study was to locate how Black identities have evolved in over the last twenty years. The students' narratives spoke to how they perceived their cultural identity, their status as citizens, and their dreams, hopes, desires and aspirations, being raised in a contemporary British society. Consistent with a racist ideology, in the educational and other areas, the study found that British historical racial constructs of the Black immigrant was as an underachiever, an assertion that is predicated on language deficits, differences in culture, family practices, and adjustment problems. Modood and Shiner (1994) argue that this stereotype, which at its best is hinged on cultural determinism and pathology, has become the defining variable and platform for assessing Black children's educational experiences. Rassool argues that Black youth experience of school is jaundiced by the racially organized rejection of their culture and values, represented by their accent (Levine, and Campbell, 1972), traditional mode of dressing and cultural celebration. In their stead, they have been forced to adopt Western symbols of success and upward mobility in order to fit in and reduce the ridicule. If they bring fufu, yam, kenke, egusi, or ogbono soup or any of their cultural food to school, they are scoffed at, because these are not mainstream (Gurin, and Epps, 1975).

Rassool (1999) found that the rejection by mainstream society is not always negative as some Black youth become defiant to this rejection, by confronting and embracing their traditional cultural practices, as part of the "psychological and geographical pilgrimage to the homeland." This "pilgrimage to the homeland," as Rassool explained, presents in the form of a pay back by disidentification with the majority culture, which they feel has "rubbed them the wrong way." Rassool's study, as encouraging as it appears, does not speak to the findings in this and other studies, where rejection by the dominant society rather than engender defiance on the minority youth, tends to push them towards rejecting their own culture and sometimes community in their strive to fit in and be accepted by the dominant society.

Lee (1998) presents concise, but also comprehensive suggestions for inclusivity in the classrooms in his work entitled "Anti-Racist Education: Pulling Together to Close the Gaps." Although most of the sections of our study incorporated anti-racist recommendations for addressing the perceived underachievement of minority and new immigrant learners, this final section of recommendations for an anti-racist, therefore multicultural education borrows heavily from Lee's treatise. Our findings regarding adaptation of new immigrant learners to the Canadian classrooms, unearthed voids in the educational system and practice, which resonate with Lee's identification of what he referred as "three gaps" [embedded in systemic racism] required to be plugged in order to actualize an anti-racist, multicultural education. The Three Gaps are embedded at the (1) Racial, (2) Individual and (3) Community levels of interaction and abstraction. For Lee, anti-racism education has everything to do with Equity and Equality or the lack thereof as represented by the following exclusion variables:

1. A purposeful underrepresentation and misrepresentation of people of color in pedagogical material

2. Underrepresentation, sometimes, non-existence of people of color on Advanced Placement Classes and school faculties

3. The discounting of home and community knowledge, language and lived experiences of racialized and students of color in the pedagogical process

4. Applying assessment tools that are in dissonance with the lived experiences of students of color

5. Perpetuating the myth of "Model Minority" that presumes that some designated racial and cultural groups have little to no value for education, therefore children and youth from these populations are lacking in or decrepit of intellectual capacity to experience successful school and educational outcomes 
6. "Dumbing down" pedagogy, [Tracking] that denies students of color intellectual stimulation and challenge in learning activities-they are Tracked into Vocational sectors

7. Lack of Technological equipment, materials, including texts and infrastructural decay of schools predominated by students of color

8. School governance that eliminates or stifles parents' voices

9. Segregation and prohibition of legitimate assembly of minority students, during lunches, break and other informal environments

10. High-handed, frequent and disproportionate reprisals-detentions, suspensions, expulsions, against students of color for minor transgressions

11. School materials, structured inequalities in relationships, and institutional practices that miseducate White students as they frequently occur and are witnessed by them (Lee, 1998).

We have already enunciated the 3 major Gaps identified by Lee (1998) as implicated in the sometimes, abysmal performance of colored and minority students within the educational systems. Let us examine each gap as succinctly as possible to help underscore the type of recommendation that would be fit and appropriate as intervention.

\subsubsection{Gap 1. Racial Gap.}

This type of gap is represented by generally poor educational outcomes experienced by African American, Latino/Hispanic and Native American students as a racialized group, when juxtaposed with their White cohort and a few Asian [Model Minority] students as a group with better educational outcomes.

\subsubsection{Gap 2. Individual [Micro-level] Gap:}

The gaps as we know them are not mutually exclusive but interwoven in such ways that one gap, not only leads to the other, but exacerbates unsavory outcomes in another. Gap number two is represented by Individual and personal gaps of African American, Latino/Hispanic and Native American students. In this configuration, some colored and minority students arrive the front porch of the schools with confidence and a repertoire of valuable lived experience, languages and other skills, but which are gradually discounted into oblivion. By the time they are ready to leave the school environment, the discourses of racism, including a culturally invalidating, disenfranchising classrooms where they must enter each and everyday, low expectations by teachers, would have robbed them of these skills, "delearning' and rendering them less capable, less confident and less worthy. A significant variable in engaged learning, which is the curiosity to know and ability to learn, languages they brought with them to school initially, are stolen, due to a conspiracy of devaluation of their ability to learn. The gap that has accumulated at the individual level translates into outcomes for the gaps at the social group level, posing serious concern for teachers and their employers.

\subsubsection{Gap 3. Community [Mezzo and Macro] Level Gap:}

Gap three speaks to the constructs and discourses of racism, which ab initio promotes the growth of one community, usually based on race, while it denies others the same appurtenances of growth and development that it has privileged itself and taken for granted. The indices for growth and development include but are not limited to a sound education, disproportionate health and its outcomes, and equal protection under the existing laws. Gap 3 arguably impacts negatively on racial and cultural communities on the short term, due to being denied the same opportunity to develop to their full potentials. On the long term, it erodes the fabrics of sustainable growth for the whole society, due to the inevitable fact that the marginalized are equally members of the same society as the marginalizers. National Center for Education Statistics (2004) finds that the race based inequities that are the bane of communities of color have outcomes for a 40 percent drop-out rate among Latino high school students, even when they comprised only 17 percent of the total youth population.

Still on the issue of gap or disproportionality in colored communities, Eckholm of The New York Times (2006) found that "In 1995, 16 percent of Black men in their 20s who did not attend college were in jail or prison; by 2004, 21 percent were incarcerated. By their mid-30s, 6 in 10 Black men who had dropped out of school had 
spent time in prison" (para.11). In deconstructing the myth of the Asian genius, Le (2001) argued for instance that:

\begin{abstract}
"Vietnamese Americans only have a college degree attainment rate of $16 \%$, only about one-quarter the rate for other Asian American ethnic groups. Further, Laotians, Cambodians, and Khmer only have rates around 5\%. The cultural stereotype that "all Asians are smart" puts a tremendous amount of pressure on many Asian Americans. Many, particularly Southeast Asians, are not able to conform to this unrealistic expectation and in fact, have the highest high school dropout rates in the country. Again, not all Asian Americans are the same" (para.7)
\end{abstract}

In light of this finding, institutionally entrenched racism and "othering" create the gap at the community level, which then translates into the school and educational-based academic gap existing at the group and individual levels of abstraction. Therefore, any attempts to close the gaps at the educational levels must control for the disproportionality that exist at the community level, or risk an abysmal failure in outcome. For Lee (1998), the gaps that mire students of color [including new immigrant learners] in the arena of poor educational outcomes and failure are located in the historical, social and political understanding of the constructs and operationalization of racism. These constructs create the policies and structures in institutions, the professional and personal development of teachers and educators, including their pedagogical delivery at the classroom level; in the hallways during recesses and lesson changes; during parent/teacher meetings and all spheres of the educational endeavor. Since the construction and application of power creates intersectionalities between the minority student, their teachers and school administration, and educational outcomes, an anti-racist paradigm must encapsulate the following four principles:

1. Intervention that emphasizes both the situational and systemic inequalities

2. Intervention that emphasizes good and conscientious teaching

3. Intervention that emphasizes that teachers and educators of children are able to learn to [transcend mediocrity] pursue excellence

4. Intervention that must highlight inequities that are constructed by race, in addition to equity measures and paradigms, designed as path to racial equality

The following provides an in-depth analysis of the disproportionality-closing paradigms in the interest of minority students at the micro and mezzo levels and the promotion of social justice at the macro level of society.

\title{
10.2. Situational and Systemic gap-closing paradigms
}

The argument for this paradigm posits that the variables of situational and systemic exclusion of minority students cannot be mutually exclusive. What this means is that routing one, while leaving the other, creates a hydra head that can only rejuvenate and continue from where it was interrupted. Individual teachers and educators from the majority population engage in systemic inequities at the practice levels, and at specific times and situations. In light of racism presenting as systemic rather than episodic entity, its practice must be confronted and disrupted each and every time it rears its head, until its roots are reached. Lee's anecdotal use of Advanced Placement classes for students of all races, raised the standards, rather than lower it as had been the systemically propagated [stereotypical] belief by teachers and educators. In the case of the Advanced Placement classes, teachers and educators from the dominant population constructed and perpetuated a belief that African American and Latino parents, owning to their pathology, did not understand the workings of the systems, including education. They further argued that even when these minority parents had a grasp of the workings of the system, would show apathy towards doing what it takes [such as meetings with teachers and the students] to see their children advance (Lee, 1998).

However, the fault lay, not with the parents, but the rigid educational tracking system that is practiced in schools across the United States. Tracking, also known as ability-grouping systems is a systemic assignment that begins at the kindergarten level with the IQ screening. Curriculum tracking hinges on expected achievement and entails the separation of secondary school students into academic and vocational tracks. Here, students are streamed into different levels of the same course. Sometimes, they are assigned to a course having a different curriculum that depending on the outcome of the IQ tests is either less or more rigorous (Brunello and Checchi, 2007; Hanushek and Woessmann, 2006; Oakes, 2005; Lucas, 1999). 
The stereotypes and erroneous assumptions [mainly accusation of disinterested parents of color] were deconstructed and debunked, when special invites were sent to all parents, allotting particular blocks of time for attending the meeting. Most of the parents of the minority students attended, using several, sometimes challenging modes of transport to get to and from the school, as well as complied with the required directives. Systemic racism was manifested by the fact that the teachers and Counselors had actively encouraged students from the majority culture to enroll into the Advanced Placement classes, which gave them added impetus to enroll. On the contrary, African American and Latino students of the same cohort were not only not advised of the possibility of enrolling, but some felt that they were actively discouraged from participating in the program because it would be "too challenging for them" [emphasis added]. With the active involvement of the parents and caregivers of the minority students, they began to encourage and some mandate their charges to enroll in the Advanced Placement programs, increasing their number exponentially and consequently showing encouraging signs of bridging the educational gap, a gap that was created in the first instance by situational and systemic tracking manipulations. Proponents of this gap-closing theory believe that the sustenance of detracking will promote the developmental growth of minority students to their fullest potentials, rather than the current racially motivated act of diverting them to vocational education (Lee, 1998).

\subsection{Intervention that emphasizes good and conscientious teaching}

\subsubsection{Questioning and eliciting answers}

The proponents of the good teaching model argue that teachers' question and answer technique could represent the difference between learning and not learning. When teachers pose a question, which elicits one or few answers from the alert "Jeopardy TV Game- type" ringers in the class, those who are not "quick-triggered" may be denied the opportunity of presenting their argument if the teacher stops. This leads to frustration for others, who may be shy or need some prodding to respond. The slow or nil response by some of the students should not be taken as an indication that they are "dumb." Ignoring such students accumulates bile, which may lead to an explosive response, concomitantly forcing a warranted, but unfair disciplinary action against such student.

\subsubsection{Using understandable language and demeanor to address students}

It suggests that using language that builds positive and reaffirming identities (Nieto, 1996, 1999) portends, not only as an all-inclusive teaching method, but also promotes sustainable student learning. This method treats each student as an expert in the field where the teacher wants them to succeed. The teacher applies cohortappropriate language to clarify what students have articulated, as well as questions, and provides everyday examples that the students can relate to. This style promotes students as teachers, by providing forum to share what they have accomplished (Lee, 1998) outside of the school setting, and then apply their expertise into the subject matter that is being taught in ways that other students can see, hear and "feel" their knowledge.

\subsubsection{Belongingness-[Linking students' lives to the school and formal curriculum]}

Pedagogy that is validated by the school translates into that worth knowing and worth writing about. In consequence, effective teaching purposefully links the lives of students to the formal curriculum in such ways that they see themselves as part of the educational agenda (Teel, Debruin-Parecki, and Covington, 1998). Students are more apt to learn and consciously articulate a subject matter if in some way they can see themselves as part of an event being taught. In the absence of this, most students, but especially minority students who often do not "see" themselves inserted into the pedagogy tend to find the subject as having little to no relevance in their lived experiences, resulting in a look warm attitude or outright rejection of such pedagogy. It may be alright to teach a Native American that Columbus traveled to America, but maintaining to such student that Columbus discovered America, even when such student's ancestors lived and roamed the New World before Columbus was ever conceived, would pose an insult and a distortion of history to the Native student. This teaching, in order to empower for self and group determination must acknowledge, validate and 
elevate the fringed status, cultures and lived experiences of such minority students if the intention is to bridge the educational disproportionality and promote social justice.

\subsection{Teaching Teachers to learn}

Our educational system is saturated with teachers from all sorts of background, but mostly from the dominant culture. While this is understandable due to historical events, what is hard to understand is why teachers fail to pay any serious attention to the kaleidoscope of colors that increasingly "creep" into their classrooms. The historical antecedents of slavery and racial discrimination in all spheres of White society, creates the burden on teachers, especially, White teachers, of educating and saturating themselves with knowledge about their students, their parents and the communities from where they emerge each day to attend their classes.

When teachers are able to examine the history and sequelae of race and racism in education, in community and group relationships, in religion, politics and every facet of our stratified society, then they would be well on their way to becoming "learning teachers" and can assist in not only closing the educational gap that were created and currently sustained by a racialized educational system, but also assist to promote an excellent pedagogical style. The use of color-blind statements, like "I don't care if you are Black or White" or "I treat all my students, Black or White the same" is an honest, but professionally misguided lie. It seeks to apply puerile cliché to render racism, not only insidious, but also invisible, even as the emasculatory practices by the "racism deniers" rage interminably, and ravage generation after generation of students of color and their entire communities (Lee, 1998).

\subsection{Promoting Equity and Equality}

Equity represents a form of "discriminatory" practice that seeks to level a previously, intentionally constructed uneven playing field. This ethos pursues social justice by not seeking to treat everyone the same way, but rather a process of using socially sanctioned mechanisms to level the playing field, but also put all on the same "page" following remediation. Equity is far from the currently White supremacist touted "reverse racism" which can only be meted by those who have power. There is no such thing as "reverse racism" in the absence of power to carry it out. Equitable social policies such as "Affirmative Action" were instituted in the United States of America to alter the outcomes of over 400 years of a severely racist system that has left painful and lasting scars-epitomized by the lack of representation, respect, rights and resources (Lee, 1998) on its recipients. The application of equity by teachers, administrators, secretaries, and everyone entrusted with educating our children, including those of color must be with an understanding that applying saline solution [the same treatment] to a bacterially infested wound, when an antibiotic [equitable treatment] is indicated is ultimately going to fail at best. At the worst, the patient could lose the body member or even die from severe infection of the wound. Equity is the precursor of equality, and until there is a conscious, conscientious effort to promote equity, there is no final destination for equality and social justice. In Canada where the government touts "Multiculturalism," means that this can only be achieved when racism has been routed at the individual, group and community levels.

\section{Conclusion}

How do teachers understand the emotional factors that can influence the academic performance of an immigrant learner? Our intention was to tease out, from this study, some problematics of current pedagogical practices and their implications for teachers' enhanced practice and efficacy. The study hinged on providing insight into the fact that any immigrant learner, who may have endured any form of change; change from one culture to another and its related acculturation stress is psychologically vulnerable to some form of distress and depression. Our attempt to provide a psychological insight into the experiences of immigrant learners is not to limit the impact of all other variables on an immigrant's life. It is to show that the unmet emotional and social needs of an immigrant learner with the uncertainties associated with acculturation stress (Bhagat, \& London, 1999) can erroneously point to a non-existent learning disability. The combination of different studies on immigration experiences conducted by psychologists and used for this study is to show the extent to which the immigrant learners' emotional incompetence can and do have a negative effect on their academic performance. 
The discomfiture is amplified, especially when a mismatch exists between their needs and the ones schools and society can provide, in their new culture (Kuperminc, Leadbeater, \& Blatt (2001).

The implication of this for educators and teachers is to provide curricula that are sensitive to an immigrant's learning needs. Teachers need to sincerely and conscientiously articulate an immigrant's background information to be aware of any adaptation experiences likely to become sources of psychological stressors to such student. Roberts and Locke (2001) see these experiences as having "affective" underpinnings to the academic life of an immigrant. Their research advises teachers to strive to identify the extent of the effect of limited English use and less interaction with peers (example, social competence in relation to academic competence (Welsh, Parke, \& O'neil, 2001) on the emotional well being of the immigrant learner.

Teachers and educators need to acknowledge the academic limitations of some immigrant learners by critically designing curricula (Nieto, 1999) that will attend to immigrant learner's needs (Eilam, 1999), a change in teachers' attitudes and their current inappropriate strategies (Teel, Debruin-Parecki, \& Covington, 1998) and the expungement of hidden, often systemic and racist curricula discourses.

\section{References}

Aw, Wayne (2009). Rethinking Multicultural Education: Teaching for Racial and Cultural Justice: Rethinking Schools Ltd.

Babbie, E. (1989, 1999, 2004). The Practice of social research. ( $5^{\text {th }}$ Ed.). Belmont, California: Wadsworth Publishing Company.

Baffoe, Michael (2011). Navigating Two Worlds: New Identity Constructions as Determinants for Successful Integration of New Black Immigrant and Refugee Youth in Canadian Society. Journal of Social Sciences, Vol. 7: 475-484. DOI: 10.3844/jssp.2011.475.484

Banks, J. A., \& Mcgee, C. A. (1997). Multicultural Education Issues and Perspectives (2nd ed.). Boston, MA: Allyn and Bacon.

Beins, B.C. (2004). Research Methods: A Tool for Life. Boston: Pearson/Allyn \& Bacon. Social Psychiatry and Psychiatric Epidemiology 38(1), 35-43.

Berger, Peter. L., and Luckmann, Thomas (1967). The Social Construction of Reality: A Treatise in the Sociology of Knowledge. NY: First Anchor Books Edition.

Bermau, E., Lang, K. \& Erez, S. (2003). Language-skill Complementarity: Returns to Immigrant Language Acquisition. Labour Economics 10(3), 265-290.

Bhagat, R. S., \& London, M. (1999). Getting Started and Getting Ahead: Career Dynamics of Immigrants. Human Resources Management Review 9 (3), 33349-365.

Bhui, K., Abdi, A. Mahad, A., Stephen, P., Mohammed, D., David, R. et al. (2003). Traumatic Events, Migration Characteristics and Psychiatric Symptoms Among Somali Refugees.

Birman, D. (1998). Biculturalism and Perceived Competence of Latino Immigrant Adolescents. Journal of Community Psychology 26(3), 335-354.

Birman, D., Trickett, E. J., \& Vinokurov, A. (2002). Acculturation and Adaptation of Soviet Jewish Refugee Adolescents: Predictors of Adjustment Across Life Domain. American Journal of Community Psychology 30(5), 585-607.

Brunello, Giorgio and Checchi, Daniele (2007). Does School Tracking Affect Equality of Opportunity? New International Evidence. Economic Policy, 52:781-861.

Bruner, J. (1985). Vygotsky: A historical and conceptual perspective. In J. V. Wertsch (Ed.). Culture, Communication and Cognition (pp. 21-34). Cambridge, England: Cambridge University Press.

Campbell, Marie, L., and Gregor, Frances, M. (2004). Mapping Social Relations: A Primer in Doing Institutional Ethnography. Altamira Press.

Children's Defense Fund (2005). The State of America's Children Report. http://www.childrensdefense.org/childresearch-data-publications/data/state-of-americas-children-2005-report.html

Chiswick, Barry R.; and Miller, Paul W. (2007, August). Modeling Immigrants' Language Skills. IZA Discussion Papers No. 2974. Retrieved January 8, 2013 from http://www.iza.org/en/webcontent/publications/papers/viewAbstract?dp_ id $=2974$

Connolly, P. (1998). Racism, Gender Identities and Young Children: Social Relations in a Multi-Ethnic Inner-City Primary School. London \& New York: Routledge.

Creswell, J. W. (1998). Qualitative Inquiry \& Research Design: Choosing among Five Traditions. London: Sage Publications.

Dei, G. J. (1996). Anti-racism Education: Theory \& Practice. Halifax Nova Scotia: Fernwood Publishing. 
Dei, G. J. \& Agnes, M. Calliste. (2000). Power, Knowledge \& Anti-Racism Education: Critical Reader. Halifax: Fernwood Publishing.

Dei, G. J.; Sonia V. James-Wilson; and Jasmin Zine. (2002). Inclusive Schooling: A Teacher's Companion to Removing the Margins. Toronto : Canadian Scholars' Press.

Delwyn \& Tattum, E. (1992). Social education and Personal Development. London: David Fulton Publishers.

Dentler, R. A. \& Hafner, A. L. (1997). Hosting newcomers: Structuring Educational Opportunities for Immigrant Children. New York \& London: Teachers College Press.

Dixson, A.D., and Celia. K. Rousseau. (Eds.) (2006). Critical Race Theory in Education: All God's Children Got a Song. New York: Routledge.

Dominelli, L. (1997). Anti-racist social work. A challenge for White practitioners. Basingstoke: Macmillan.

Dumont, M., \& Provost, M. A. (1999). Resilience in Adolescents: Protective Role of Social Support, Coping Strategies, Self-esteem, and Social Activities on Experiences of Stress and Depression. Journal of Youth and Adolescence 8(3), 343-363.

Dunn, R., Dunn, K., \& Perrin, J. (1994). Redesigning the Educational Environment: Teaching Young Children Through their Individual Learning Styles. Needlam Height, MA: Allyn and Bacon.

Duran, B. J., Dugan, T., A. \& Weffer, R. (1998). Language Minority Students in High School: The Role of Language in Learning Biology Concepts. Science Education 82(3), 311-341.

Durán, Richard, Jane Durán, Jane Rosita Ramirez, and Deborah, Perry-Romero (2004). The Immigrant Parents' Computer Literacy Project: A Strategies Guide for Implementation. Center for Research on Education, Diversity \& Excellence. Santa Barbara: University of California.

Eckholm, Erik (2006, March 20). "Plight Deepens for Black Men, Studies Warn." The New York Times. Retrieved from http://www.nytimes.com/2006/03/20/national/20blackmen.html?pagewanted=all\&_r=0

Eilam, B. (1999). Toward the formation of a "Cultural Mosaic": A case study. Social Psychology of Education 2(3), 263296.

Exposito, S., \& Favala, A. (2003). Reflective Voices: Valuing Immigrant Students and Teaching with Ideological Clarity. The Urban Review 35(1), 73-91.

Finch, B. K. \& Vega, W. A. (2003, July). Acculturation Stress, Social Support, and Self-related Health among Latinos in California. Journal of Immigrant Health. Vol. 5, No. 3, pp. 109-117.

Fleras, A. \& Elliot, J. L. (2003). Unequal Relations: An Introduction to Race \& Ethnic Dynamics in Canada. Ontario: Prentice-Hall.

Fleras, A. \& Elliott, J. L. (2002). Engaging Diversity: Multiculturalism in Canada. Canada: Nelson/Thomson Learning.

Fontana, A. \& Frey, J. H. (2000). The interview: From Structured Questions to Negotiated Text. In N. K. Denzin. \& Y. S. Lincoln. (Eds.), Handbook of Qualitative Research (pp.645-672). London: Sage Publications, Inc.

Foster, K.M. (2005). Diet of Disparagement: The Racial Experiences of Black Students in a Predominantly White University. International Journal of Qualitative Studies in Education 18 (4), 489-505.

Foster, M. (1991). Just Got to Find a Way: Case Studies of the Lives \& Practice of Exemplary Black High School Teachers. In M. Foster (Ed.), Into Schools \& Schooling (pp.273-309). New York, NY: AMS Press.

Freire, P (1985). The Politics of Education: Culture, Power, \& Liberation. South Hadley, MA: Bergin \& Garvey.

Garfinkel, Harold (1967), Studies in Ethnomethodology, Englewood Cliffs, N.J.: Prentice-Hall.

Ghosh, R. (2002). Redefining Multicultural Education (2nd ed.). City? Canada: Nelson \& Thomson Learning.

Giorgi, Amedeo (1975). "An Application of Phenomenological Method in Psychology," in Amedeo Giorgi, Constance T. Fischer, and Edward L. Murray (Eds.), Duquesne Studies in Phenomenological Psychology: Volume II (pp. 82-103), Pittsburgh: Duquesne University Press.

Graham, G., \& Jenkins, A. (Eds.). (1992). Teaching Large Classes in Higher Education: How to Maintain Quality with Reduced Resources. London: Kogan Page.

Gredler, M E. (1997). Chapter 10: Lev S. Vygotsky's Sociohistorical Theory of Psychological Development. Learning and Instruction: Theory into Practice (3rd ed.), pp. 237-273). Toronto, Canada: Prentice-Hall.

Gurin, P., \& Epps, E. G. (1975). Black consciousness, identity, \& achievement. New York: John Wiley \& Sons.

Hammersley, M. (2000). Taking Sides in Social Research: Essays on Partisanship and Bias. London ; New York : Routledge.

Hanushek, Eric and Woessmann, Ludger (2006). Does Educational Tracking Affect Performance and Inequality? Differences-in-Differences Evidence Across Countries. The Economic Journal, 116:C63-C76.

Hecht, D. B., Inderbitzen, H. M., \& Bukowski, A. (1998). The Relationship Between Peer Status and Depressive Symptoms in Children and Adolescents. Journal of Abnormal Child Psychology 26(2), 153-160.

Henry, F., Tator, C., Mattis, W, \& Rees, T. (2000). The Colour of Democracy: Racism in Canadian Society (2nd ed.). Toronto, Canada: Harcourt Brace \& Company. 
Horenczyk, G., \& Tatar, M. (1998). Friendship Expectations Among Immigrants and their Host Peers. Journal of Adolescence 21(1), 69-82.

Hovey, J. D., \& Magana, C. (2000). Acculturation Stress, Anxiety, and Depression Among Mexican Immigrants Farm Workers in the Midwest United States. Journal of Immigration Health 2 (3), 119-131.

Howes, C., Phillipsen, L. C., \& Peisner-Feinberg, E. (2000). The Consistency of Perceived Teacher-Child Relationships Between Preschool and Kindergarten. Journal of School Psychology 38 (2), 113-132.

Hughes, D. \& Kallen, E. (1974). Anatomy of racism: Canadian Dimensions. Montreal, ON: Harvest House.

Kiernan, Ben (2009). Blood and Soil: A World History of Genocide and Extermination from Sparta to Darfur. Yale University Press.

Kohen, D. E., Hertzman, C., \& Weins, M. (1998). Environmental Changes and Children's Competences. (Working Papers No. W-98-25E). Hull, Canada: Applied Research Branch Strategic Policy. Human Resources Development.

Kuperminc, G. P., Leadbeater, B. J., \& Blatt, S. J. (2001). School Social Climate and Individual Differences in Vulnerability to Psychopathology Among Middle School Students. Journal of School Psychology 39(2), 141-159.

Kvale, Steinar and Brinkmann, Svend (2009). Interviews: Learning the Craft of Qualitative Research Interviews. Thousand Oaks, CA: Sage.

La Greca, A. M., \& Lopez, N. (1998). Social Anxiety Among Adolescents: Linkage with Peers Relations and Friendships. Journal of Abnormal Child Psychology 26 (2), 83-94.

Le, C.N. (2001). A Closer Look at Asian Americans and Education. School of Education at John Hopkins University - New Horizon for Learning. Retrieved from http://hawaii.edu/religion/courses/Asian-Americans-Education.pdf

Lee, D. (1997). What Teachers Can Do to Relieve Problems Identified by International Students. New Directions for Teaching and Learning, 70, 93-100.

Lee, Enid (2002). Taking Multicultural, Anti-Racist Education Seriously. Focus on Multicultural Education, Vol. 10, No. 1. Retrieved December 27, 2012 from http://thenotebook.org/fall-2002/021466/taking-multicultural-anti-racisteducation-seriously

Lee, Enid (1998). "Anti-Racist Education: Pulling Together to Close the Gaps." In Beyond Heroes and Holidays: A Practical Guide to K-12. Anti-Racist Multicultural and Staff Development. Network of Educators on the Americas.

Lee, M. \& Sheared, V. (2002). Socialization and Immigrant Students' Learning in Adult Education Programs. New Directions for Adult and Continuing Education (96), 27-36

LeCompte, M. D. \& A.G. Dworkin. (1991) Giving Up on School: Student Dropouts and Teacher Burnouts. Newbury Park, CA: Corwin Press.

Levine, R. A. \& Donald, T. Campbell. (1972), Ethnocentrism: Theories of Conflict, Ethnic Attitudes \& Group Behavior. New York; London; Toronto: John Wiley \& Sons, Inc.

Lewis, R. B., and Doorlag, D. H. (1999). Teaching Special Needs Students in the Mainstream. (3rd ed.). New York: Macmillan Publishing Company.

Lucas, Samuel R. (1999). Tracking Inequality: Stratification and Mobility in American High Schools (Sociology of Education Series). Teachers College Press.

MacDonald, V., \& Speece, D. (2001). Making time: A Teacher's Report on Her First Year of Teaching Children with Emotional Disabilities. Journal of Special Education 35(2), 84-91.

Martin, Ellen Marie (Peterson) (2011). "Digital Natives and Digital Immigrants: Teaching with Technology." Education Doctoral Theses. Paper 7. Boston, MA: Northeastern University. http://hdl.handle.net/2047/d20002139

Matthews, G., Zeidner, M., \& Roberts, R. D. (2002). Emotional Intelligence: Science and Myth. Cambridge, MA: MIT Press.

McDonnel, L. \& Hill, P. (1993). Newcomers in American Schools: Meeting the Educational Needs of Immigrants Youths. Santa Monica, CA: Rand.

Murray, C., \& Greenberg, M. T. (2000). Children Relationship with Teachers and Bond with School: An Investigation of Patterns and Correlates in Middle Childhood. Journal of School Psychology 38(5), 423-445.

Nakkula, M.J., and Eric, Toshalis (2006). Understanding Youth: Adolescent Development for Educators. Cambridge, MA: Harvard Education Press.

National Center for Education Statistics (2004). The Condition of Education. Institute of Education Sciences. U.S. Department of Education.

Ng, C. F. (1998). Canada as a New Place: The Immigrant's Experience. Journal of Environmental Psychology 18(1), 55-67.

Nieto, S. (1999). The Light in Their Eyes: Creating Multicultural Learning Communities New York: Teachers College, Columbia University.

Nieto, S. (1996). Affirming Diversity: The Sociopolitical Context of Multicultural Education (2nd ed.) New York: Longman Publishers. 
Northwest Regional Educational Laboratory (2011).Improving Education for Immigrant Students: A Resource Guide for K-12 Educators in the Northwest and Alaska. Retrieved from http://www.nwrel.org/cnorse/booklets/immigrantion /5.html.

Oakes, Jeanine (2005). Keeping Track: How Schools Structure Inequality, Second Edition. Yale University Press.

Ogbuagu, B.C. (2012). Nice CV! You Will Hear From Us: Canadian Labor Market and the Phenomenology of the Marginalized Ethnic Professional Migrant. Journal of Social Sciences, Vol. 8, Issue 1, pp.1-12.DOI: 10.3844/jssp.2012.1.12

Phinney, J. S., Romero, I., Nava, M., \& Huang, D. (2001). The Role of Language, Parents, and Peers in Ethnic Identity Among Adolescents in Immigrant Families. Journal of Youth and Adolescence 30(2), 135-153.

Power, Samantha (n.d). Never Again: The World's Most Unfulfilled Promise. PBS Frontline,

Human Rights Initiative at the Kennedy School of Government at Harvard University. Retrieved December 27, 2012 from http://www.pbs.org/wgbh/pages/frontline/shows/karadzic/genocide/neveragain.html

Rassool, N. (1999). Flexible Identities: Exploring Race \& Gender Issues Among a Group of Immigrant Pupils in an Innercity Comprehensive School. British Journal of Sociology of Education, 20, 1, 23-36.

Ritsner, M., \& Ponizovsky, A. (2003). Age Difference in Stress Process of Recent Immigrants. Comprehensive Psychiatry 44(2), 135-141.

Roberts, A. \& Locke, S. (2001). Tending School: A Forum on the Experiences of Refugee and Immigrant Students in the United States. Interchange 32(4), 375-393.

Roeser, R. W., Wolf, K., \& Strobel, K. R. (2001). On Relation Between Social-emotional And School Functioning During Early Adolescence: Preliminary Findings from Dutch and American Samples. Journal of School Psychology 39(2), 111-139.

Sandoval, D. (2002, Fall). Review of the Book (Educating our Black children: New directions and radical approaches), MJE, Vol. 37, No. 3, 469-474. New York, NY.: Routledge Falmer, A member of Taylor \& Francis Publishing, Inc.

Schutz, A. (1967). The Phenomenology of the Social World (G. Walsh \& F. Lenhert, Trans.). Chicago: Northwestern University Press.

Stiffman, A. R., \& Davis, L. E. (Eds.) (1990). Ethnic Issues in Adolescent Mental Health. London, England: Sage Publications.

Teel, K. M., Debruin-Parecki, A., \& Covington, M. V. (1998). Teaching Strategies that Honor and Motivate Inner-city African-American Students: A school/University Collaboration. Teaching and Teacher Education 14(5), 479-495.

Torczyner, J.L. (1997). Diversity, Mobility \& Change: The Dynamics of Black Communities in Canada. Canadian Black Communities Demographic Project. Preliminary Findings. Montreal, Quebec: McGill University, McGill Consortium for Ethnicity \& Strategic Social Planning.

Turner, G. (1999). Peer Support and Young People's Health. Journal of Adolescence 22 (4), 567-572.

Ullman, C., \& Tatar, M. (2001). Psychological Adjustment Among Israeli Adolescent

Immigrants: A Report on Life Satisfaction, Self-concept, and Self-esteem. Journal of Youth and Adolescence 13(4), 449463.

Vernez, G., Abraharmase, A. F., \& Quigley, D. D. (1996). How Immigrants Fare in U.S. Education. Santa Monica, CA: Ramel Corporation.

Welsh, M., Parke, R. D., \& O'neil. R. ( 2001). Linkages Between Children's Social and Academic Competence: A Longitudinal Analysis. Journal of School Psychology 39(6), 463-481.

Wertsch, J. V., \& Tulviste, P. (2000). L. S. Vygotsky and Contemporary Developmental Psychology. Developmental Psychology 28(4), 21-34.

Wien, F. C. (1976). Opinions for the Center: The Position of Minorities in a Canadian University. Institute of Public Affairs, Dalhousie University Institute of Public Affairs, Halifax, Canada: Dalhousie University.

Wierzbicka, A. (1999). Emotions Across Languages and Cultures: Diversity and Universals. Cambridge, UK: Cambridge University Press.

Wilson, J. D. (1984). Multicultural Programs in Canadian Education. In R. J. Samuda (Eds.), Multiculturalism in Canada: Social and Educational Perspectives (pp. 62-77). Toronto, ON: Allyn and Bacon.

Wright, C. (2003). Saving the Differences: Essays on Themes from Truth and Objectivity. Cambridge, Mass.: Harvard University Press. 
